\title{
Rotationally Augmented Flow Structures and Time Varying Loads on Turbine Blades
}

Conference Paper NREL/CP-500-40982 January 2007

\section{Preprint}

S.J. Schreck

To be presented at the $45^{\text {th }}$ AIAA Aerospace Sciences Meeting and Exhibit, Wind Energy Symposium

Reno, Nevada

January 8-11, 2007
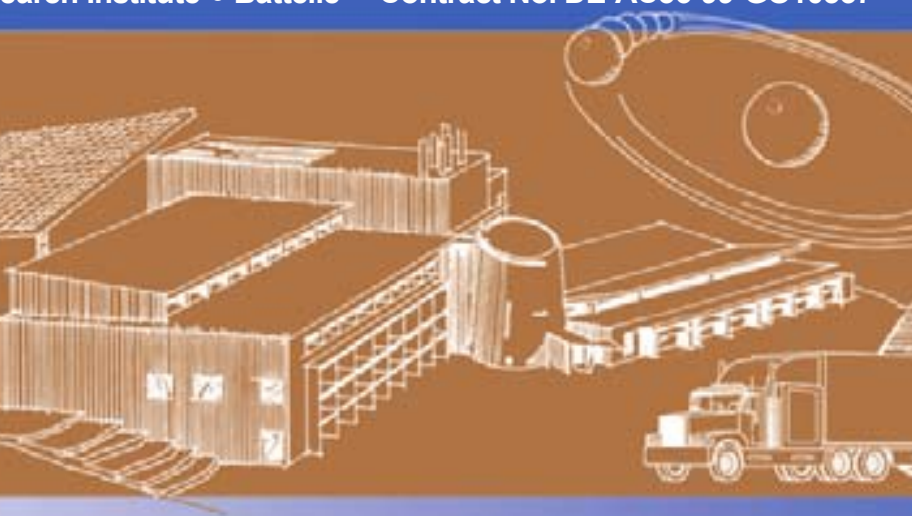


\section{NOTICE}

The submitted manuscript has been offered by an employee of the Midwest Research Institute (MRI), a contractor of the US Government under Contract No. DE-AC36-99G010337. Accordingly, the US Government and MRI retain a nonexclusive royalty-free license to publish or reproduce the published form of this contribution, or allow others to do so, for US Government purposes.

This report was prepared as an account of work sponsored by an agency of the United States government. Neither the United States government nor any agency thereof, nor any of their employees, makes any warranty, express or implied, or assumes any legal liability or responsibility for the accuracy, completeness, or usefulness of any information, apparatus, product, or process disclosed, or represents that its use would not infringe privately owned rights. Reference herein to any specific commercial product, process, or service by trade name, trademark, manufacturer, or otherwise does not necessarily constitute or imply its endorsement, recommendation, or favoring by the United States government or any agency thereof. The views and opinions of authors expressed herein do not necessarily state or reflect those of the United States government or any agency thereof.

Available electronically at http://www.osti.gov/bridge

Available for a processing fee to U.S. Department of Energy and its contractors, in paper, from:

U.S. Department of Energy

Office of Scientific and Technical Information

P.O. Box 62

Oak Ridge, TN 37831-0062

phone: 865.576 .8401

fax: 865.576 .5728

email: mailto:reports@adonis.osti.gov

Available for sale to the public, in paper, from:

U.S. Department of Commerce

National Technical Information Service

5285 Port Royal Road

Springfield, VA 22161

phone: 800.553 .6847

fax: 703.605.6900

email: orders@ntis.fedworld.gov

online ordering: http://www.ntis.gov/ordering.htm 


\title{
Rotationally Augmented Flow Structures and Time Varying Loads on Turbine Blades
}

\author{
Scott J. Schreck ${ }^{1}$ \\ NREL's National Wind Technology Center, 1617 Cole Boulevard, Golden, CO 80401
}

\begin{abstract}
[Abstract] Blade rotation routinely and significantly augments aerodynamic loads during zero yaw operation of horizontal axis wind turbines. To better understand the flow physics underlying this phenomenon, time dependent blade surface pressure data were acquired from the NREL Unsteady Aerodynamics Experiment, a full-scale HAWT tested in the NASA Ames $80 \mathrm{ft}$ x $120 \mathrm{ft}$ wind tunnel. Records of time varying surface pressure were analyzed to extract mean flow field structure and normal force coefficient standard deviation during operating conditions that included rotational augmentation. Clear relationships were identified between mean flow field state and the magnitude of time variations in normal force coefficient. Model results showed that the level of these time variations in normal force coefficient were significant compared to time varying aerodynamic loads elicited by turbulent inflows.
\end{abstract}

$\begin{array}{ll}C_{n} & \text { normal force coefficient }(\mathrm{N} / \mathrm{qc}) \\ c & \text { chord length }(\mathrm{m}) \\ c_{p} & \text { pressure coefficient }\left(\left(\mathrm{p}-\mathrm{p}_{\infty}\right) / \mathrm{q}\right) \\ H A W T & \text { horizontal axis wind turbine } \\ L F A & \text { local inflow angle }(\mathrm{deg}) \\ \mathrm{L}_{\mathrm{IMP}} & \text { impingement length }(\mathrm{x} / \mathrm{c}) \\ \mathrm{L}_{\mathrm{SEP}} & \text { separated length }(\mathrm{x} / \mathrm{c}) \\ N & \text { Normal force or Newton } \\ N F A C & \text { National Full-Scale Aerodynamics Complex } \\ p & \text { static pressure }\left(\mathrm{N} / \mathrm{m}^{2}\right) \\ p_{\infty} & \text { freestream static pressure }\left(\mathrm{N} / \mathrm{m}^{2}\right) \\ q & \text { dynamic pressure }\left(\mathrm{N} / \mathrm{m}^{2}\right) \\ r & \text { radial distance from hub }(\mathrm{m}) \\ R & \text { blade length }(\mathrm{m}) \\ R P M & \text { revolutions } / \text { minute } \\ S D & \text { standard deviation } \\ U_{l o c} & \text { local inflow speed }(\mathrm{m} / \mathrm{s}) \\ U_{\infty} & \text { test section speed }(\mathrm{m} / \mathrm{s}) \\ x & \text { chord location }(\mathrm{m}) \\ \alpha & \text { angle of attack }(\text { deg }) \\ \theta & \text { blade pitch angle }(\mathrm{deg}) \\ U A E & \text { Unsteady Aerodynamics Experiment }\end{array}$

\footnotetext{
${ }^{1}$ Senior Engineer II, Applied Research Division, Associate Fellow

Employees of the Midwest Research Institute under Contract No. DE-AC36-99GO10337 with the U.S. Dept. of Energy have authored this work. The U.S. Government retains, and the publisher, by accepting the article for publication, acknowledges that the U.S. Government retains a non-exclusive, paid-up, irrevocable, worldwide license to publish or reproduce the published form of this work, or allow others to do so, for U.S. Government purposes.
} 


\section{Introduction}

Horizontal axis wind turbines (HAWTs) routinely experience unanticipated aerodynamic loads. Elevated aerodynamic loads impose high stresses on blades and structural components, appreciably shortening machine service life. In addition, aerodynamic load fluctuations produce torque variations that adversely impact power quality and degrade transmissions. These and other factors arising from unpredicted and excessive aerodynamic loading drive up the overall cost of energy. Failure to reliably predict aerodynamic loads is due principally to a lack of accurate methods for modeling wind turbine blade aerodynamics. This situation, in turn, derives strongly from the complex nature of wind turbine blade aerodynamics and incomplete comprehension of the fluid dynamics that govern them.

Flow fields elicited by HAWT blades are highly complex due to the simultaneous presence and interaction of three-dimensionality, unsteadiness, separation, and rotational influences. Previous field experiments have established that dynamic stall routinely occurs on HAWT blades, producing energetic vortex structures responsible for dramatic force and moment amplifications.[1-5] Recently, dynamically stalled blade flow fields have been investigated in detail, significantly improving comprehension of the three-dimensional vortex dynamics responsible for these flows.[6-8]

Typically, dynamic stall dominates turbine blade flow fields at large to moderate yaw angles, and remains prominent even under low yaw conditions. However, low yaw angles appreciably attenuate dynamic stall effects, permitting emergence of rotational influences. At zero yaw, rotational effects comprise the principal increment to blade aerodynamic response.

Currently, rotational influences remain incompletely characterized and understood. The widely cited experiments of Himmelskamp [9] indicate that stall delay and lift enhancement due to rotation were first noted for aircraft propellers. To explain these results, radial thinning and chordwise acceleration of the steady boundary layer, due to centrifugal forces and Coriolis effect, were postulated. A complementary theoretical analysis was performed by Banks and Gadd [10] for steady laminar boundary layers on a rotating blade at small incidence. They concluded that rotational effects could stabilize the boundary layer against separation, if the linear adverse external velocity gradient is sufficiently small.

Subsequent experimental and analytical research was carried out in the rotorcraft field. McCroskey and Yaggy [11] carried out a theoretical analysis for quasi-steady rotor blade flows with small crossflows. For zero or favorable chordwise pressure gradient, the effects of crossflow due to rotor rotation were judged beneficial, especially in regions of incipient separation, but of smaller magnitude than crossflows due to rotor translation. It was also speculated that, in strong adverse pressure gradients, the rotationally induced crossflows played a more influential role. Further rotor experiments [12] suggested that centrifugal forces move the fluid significantly outward in separated regions, but are relatively unimportant regarding aerodynamic force augmentation under these conditions.

More recent HAWT experiments, all employing surface pressure measurements, reached differing conclusions regarding the impact of blade crossflows. Using field test data, Madsen and Christensen [13] concluded rotational effects to be of minor importance compared to the influences of aspect ratio and spanwise pressure gradient. Two other experiments were carried out in wind tunnels and arrived at different conclusions. Using two-dimensional airfoil performance as a baseline, Barnsley and Wellicome [14] stated that the combination of rotational and threedimensional effects appeared to suppress the loss of leading edge suction across the entire span, compared to twodimensional behavior. Ronsten [15] used nonrotating blade data as a baseline, and noted that rotation generated significant differences in lift behavior only at the pressure measurement station farthest inboard on the blade.

Using full-scale HAWT data acquired in a wind tunnel, Schreck and Robinson [16] concluded that rotational augmentation was not driven by Reynolds number effects, prominent global unsteadiness, or sweep effects. Rather, it was associated with distinctive chordwise and spanwise pressure signatures that varied in an orderly manner in response to changes in radial location and inflow conditions. Subsequent work [17] exploited rotating blade surface pressure data to characterize boundary layer separation and shear layer impingement, and flow field structure evolution with rotational augmentation of the flow field. Closely related research $[18,19]$ correlated experimentally and computationally derived surface flow topologies for the rotating blade, finding excellent agreement and significantly generalizing comprehension of the flow field. Other work [20] isolated tip speed ratio as in independent variable, and quantified the influence of tip speed ratio on aerodynamic forces and underlying flow field structure. More recently, unsteadiness in rotational augmented flows has been experimentally identified and characterized for a bounded set of operating conditions.[21]

Attempts have been made to formalize extant knowledge of HAWT flow field rotational influences using approximate and empirical models. A model formulated by Eggers and Digumarthi [22] scaled the effects centrifugal and Coriolis effects on a low energy, deeply stalled wake residing on the blade suction surface. Snel, et 
al. [23] developed a computational model that employs a quasi-two-dimensional approximation that retains the important effects of centrifugal and Coriolis forces. Tangler and Selig [24] applied the empirical stall delay model of Corrigan and Schillings [25] to wind turbine blade flows to account for rotational and inertia effects.

To date, the principal structures and interactions underlying the mean component of blade rotational augmentation are approaching adequate characterization. In contrast, the physical relationships that give rise to the time varying component of rotational augmentation remain relatively obscure. To address this disparity, a portion of the blade surface pressure data acquired via the NREL UAE during the NASA Ames test have been analyzed to quantify the unsteady component of aerodynamic load enhancement due to rotational influences. Analysis methodologies have been applied to these data to better understand the time varying fluid dynamic mechanisms present under rotational, three-dimensional conditions. In particular, these analyses have been directed toward revealing relationships extant between the mean and unsteady components operating in the rotationally augmented blade flow field.

\section{Experimental and Modeling Procedures}

\section{A. Experimental Measurements}

The UAE HAWT has been documented in detail for earlier field testing phases of the experiment.[26-29] Several UAE configurations were tested in the NFAC $80 \mathrm{ft} \times 120 \mathrm{ft}$ wind tunnel, and are described by Hand, et al.[30] Data analyzed herein were acquired from a two bladed upwind rotor, $10.1 \mathrm{~m}$ in diameter, with zero cone angle. The rotor turned clockwise (viewed from downwind) at a constant $71.6 \mathrm{rpm}$, was stall regulated, and had a maximum rated power of $19.8 \mathrm{~kW}$. A cylindrical tower $0.4 \mathrm{~m}$ in diameter supported the turbine at a hub height of $12.2 \mathrm{~m}$ (test section centerline), with $1.32 \mathrm{~m}$ rotor overhang. This UAE configuration, mounted in the NASA Ames $80 \mathrm{ft} x 120 \mathrm{ft}$ wind tunnel, is shown in Figure 1.

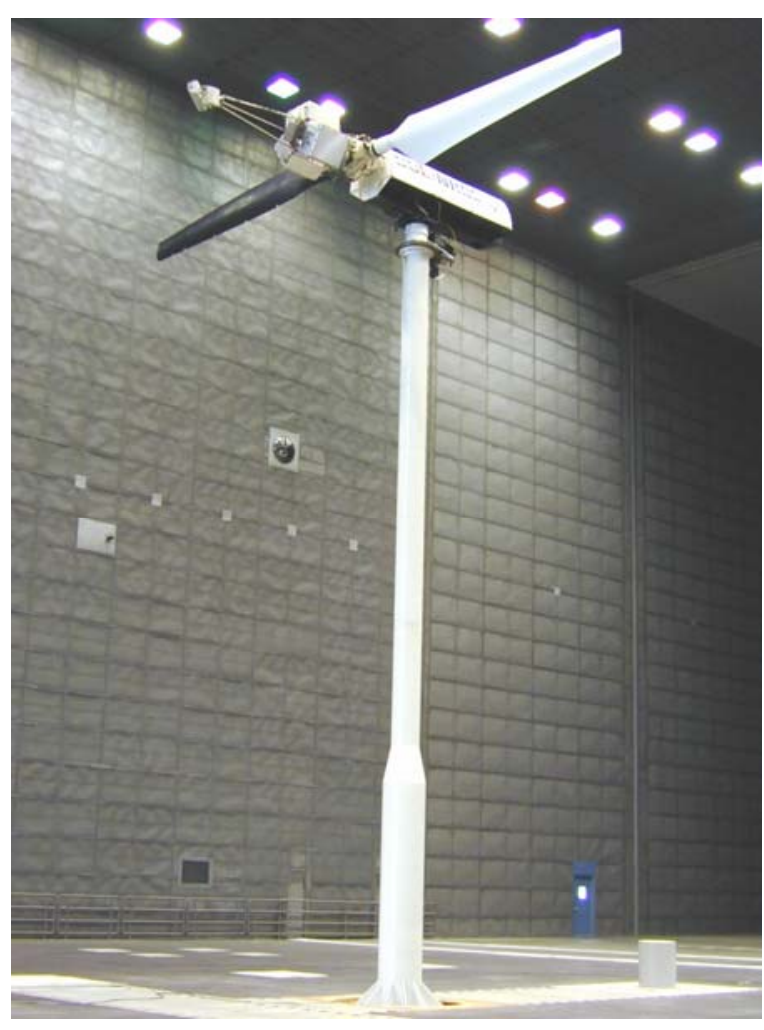

Figure 1. UAE wind turbine mounted in the NASA Ames 80 ft x 120 ft wind tunnel.

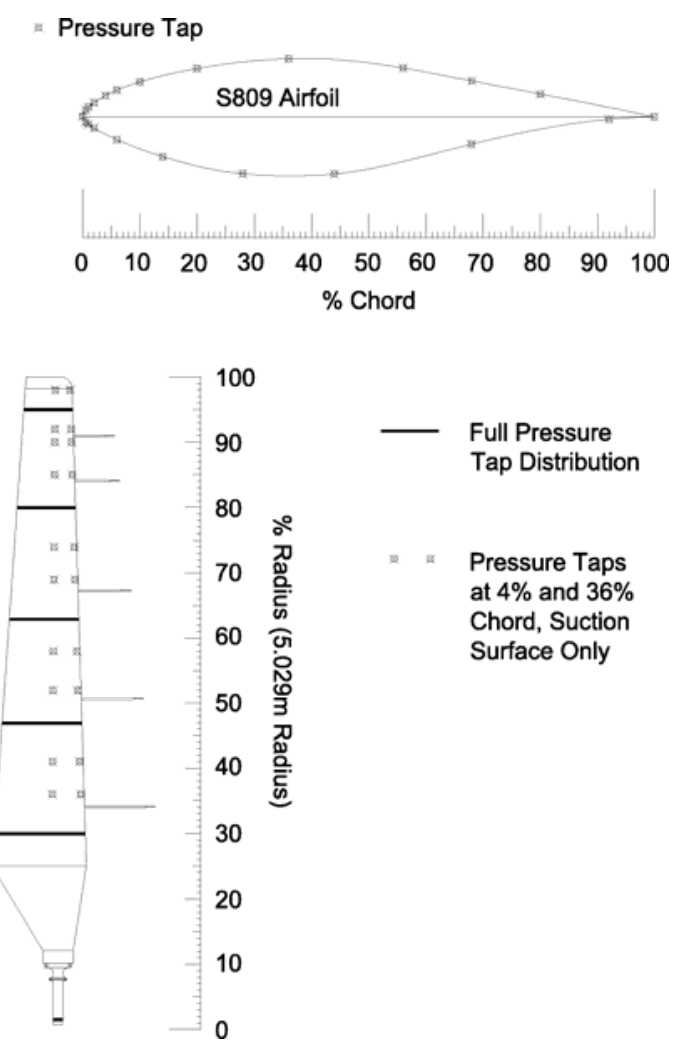

Figure 2. Blade cross-section and planform, showing pressure tap locations.

The black blade on the left side of the rotor in Figure 1 was equipped with pressure taps to acquire detailed surface pressure data. A full pressure tap distribution consisted of 22 taps distributed on the S809 airfoil section as shown in the upper portion of Figure 1. Pressure taps were more densely distributed near the blade leading edge to 
better resolve the pronounced gradients typically present there, as well as the small structures that initiate there during dynamic stall. The lower portion of Figure 2 shows that full pressure tap distributions were located at $r / R=$ $0.30,0.47,0.63,0.80$, and 0.95 . Interspersed between these five full tap distributions were ten partial pressure tap distributions, each having taps only on the suction surface at $0.04 \mathrm{c}$ and $0.36 \mathrm{c}$.

The blades used throughout the NASA Ames wind tunnel test were both twisted and tapered. The blade taper distribution is apparent in Figure 2, with maximum blade chord being $0.737 \mathrm{~m}$ at $0.25 \mathrm{R}$, and tapering to $0.356 \mathrm{~m}$ at the tip. Figure 3 documents blade twist, which decreases from $22.1^{\circ}$ at $0.25 \mathrm{R}$ to $0.0^{\circ}$ at the tip. Between $0.25 \mathrm{R}$ and the tip, blade cross section was uniform, corresponding to the S809 airfoil. The airfoil section at $0.25 \mathrm{R}$ was joined to the pitch shaft section at $0.12 \mathrm{R}$ using linear segments to yield an uninterrupted transition between these two disparate contours. The blade pitched about an axis located $0.30 \mathrm{c}$ aft of the leading edge, and centered between the blade upper and lower surfaces at that chord location. Design procedures, constraints, and measures of merit for this blade have been documented in detail.[31]

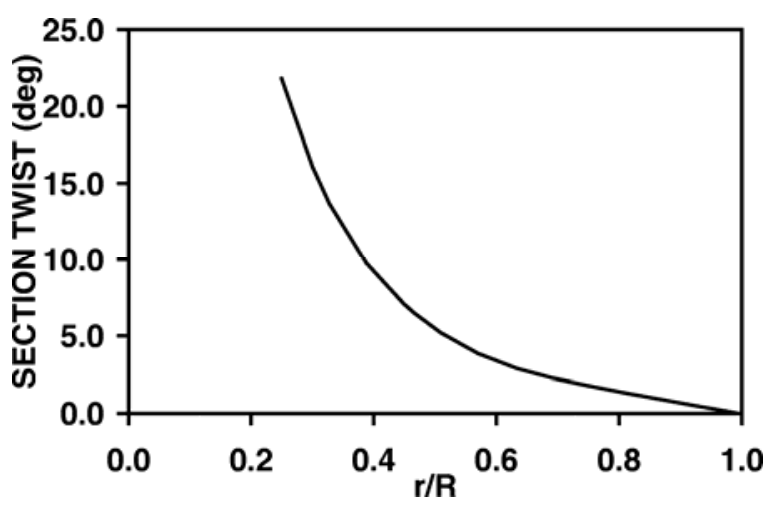

Figure 3. UAE blade twist distribution.

Surface pressure taps were flush mounted at the blade surface, and had inside diameters of $0.69 \mathrm{~mm}$. From the taps, stainless steel hypodermic tubes with inside diameters of $0.69 \mathrm{~mm}$ transmitted surface pressures to the pressure transducers. Hypodermic tubing lengths were minimized to mitigate pressure delay and dispersion effects. Pressures were measured by five Pressure Systems Incorporated ESP-32 electronically scanned pressure transducers located inside the blade near the five full pressure tap distributions. Each of the transducer pressure inputs was scanned at $520.8 \mathrm{~Hz}$. In conjunction with the tubing frequency response, this provided antialiased digitization and minimal gain variation out to $55 \mathrm{~Hz}$.[26] Test section flow speed and air properties were measured using the $80 \mathrm{ft} x$ $120 \mathrm{ft}$ wind tunnel air data system described by Zell.[32]

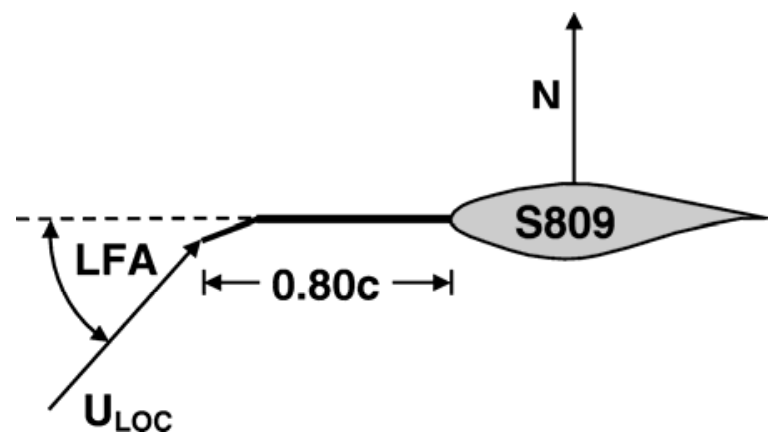

Figure 4. Definition of local inflow angle (LFA) and normal force $(\mathrm{N})$.
Inflow angles were measured near the five full pressure tap distributions using five-hole probes. As shown in Figure 4, probes were mounted on cylindrical stalks at $0.34 \mathrm{R}, 0.51 \mathrm{R}, 0.67 \mathrm{R}, 0.84 \mathrm{R}$, and $0.91 \mathrm{R}$, with the probe tip $0.80 \mathrm{c}$ upstream of the blade leading edge. Probes were angled $20^{\circ}$ downward relative to the local chord line, allowing measurement of local inflow angles between $-20^{\circ}$ and $60^{\circ}$. Five-hole probe pressures were measured using the ESP-32 transducers described above, and local inflow angle (LFA) was derived from these measurements. Consistent with Figure 4, LFA is defined as the angle between the local inflow vector $\left(\mathrm{U}_{\text {loc }}\right)$ and the local blade chord line, measured at the probe tip. Also defined in Figure 4 is normal force $(\mathrm{N})$, which is oriented perpendicular to the blade chord line, and from which $C_{n}$ is obtained.

All data were collected with the turbine rotating at a constant speed of 71.6 RPM. Turbine blade plane of rotation was maintained orthogonal to the test section centerline, yielding a yaw angle of $0^{\circ}$. Blade pitch angle was held constant at $3.0^{\circ}$. Test section velocity was varied between $5 \mathrm{~m} / \mathrm{s}$ and $25 \mathrm{~m} / \mathrm{s}$, in nominal increments of $1 \mathrm{~m} / \mathrm{s}$. At each test section velocity, a 30 second data record was acquired.

The experiments described above were carried out twice. Initially, the five hole probes and stalks were mounted on the blade, and LFA was measured concurrently with other blade aerodynamic properties. Subsequently, the probes and stalks were removed, and measurements were repeated using an otherwise identical machine configuration and virtually identical inflow conditions. This approach allowed accurate measurement of LFA while maintaining the blade flow field free of any possible intrusions due to the stalks or probes.

Time records of $c_{p}$ were integrated over the sectional chord to obtain time records of $C_{n}$. Time records of $c_{p}$ and $C_{n}$ were processed to obtain means and standard deviations for $c_{p}$ and $C_{n}$. To separate time variations due to 
rotational flow physics from tower wake influences, only those data corresponding to the upper half of the rotor disk were extracted and analyzed in the current study.

The work documented herein employs standard deviations to quantify surface pressure temporal fluctuations. To ensure that pressure measurement system frequency responses did not corrupt standard deviations, power spectral density calculations were carried out. Results confirmed that pressure fluctuations were restricted to frequencies well below previously measured pressure system cutoff frequencies.[26] Thus, pressure measurement system frequency responses were deemed negligible error sources.

\section{B. Computational Modeling}

The NASA Ames $80 \mathrm{ft} \times 120 \mathrm{ft}$ wind tunnel test section provided an inflow environment free of significant inflow turbulence or velocity gradients.[32] To quantify the $\mathrm{C}_{\mathrm{n}}$ standard deviations that would occur in response to turbulent atmospheric inflow, the NWTC YawDyn[33] and AeroDyn[34]models were employed in conjunction with turbulent inflow files generated by TurbSim[35].

All modeling results in the present work were generated using YawDyn version 12.14, with AeroDyn version 12.50. In the YawDyn input file, machine geometry and kinematics were specified consistent with documentation in ref. 30 for the "S" sequence. The " $S$ " sequence was one of several UAE test sequences carried out during testing in the NASA Ames $80 \mathrm{ft} \times 120 \mathrm{ft}$ wind tunnel. This yielded a model representation having a rigid hub, rotating at constant speed, at a fixed zero yaw angle.

In the AeroDyn input file, the blade was discretized into 21 radial elements, five of which were centered over the full pressure tap distribution locations at $\mathrm{r} / \mathrm{R}=0.30,0.47,0.63,0.80$, and 0.95 . Aerodynamic input files were generated with existing stall delay modeling techniques, modifying experimental two-dimensional S809 aerodynamics data to account for UAE blade geometric and aerodynamic three-dimensionality. Both the generalized dynamic wake and the Leishman-Beddoes dynamic stall model options available in AeroDyn were used for all modeling results described herein.

Aerodynamic response of the YawDyn/AeroDyn model was calibrated by comparing model mean $\mathrm{C}_{\mathrm{n}}$ predictions for $\mathrm{r} / \mathrm{R}=0.30,0.47,0.63,0.80$, and 0.95 , against mean $\mathrm{C}_{\mathrm{n}}$ measurements acquired by the UAE during sequence "S" wind tunnel testing. Then, based on these comparisons, AeroDyn aerodynamics input files were adjusted accordingly. To replicate wind tunnel conditions, calibration model runs were carried out with zero vertical and horizontal shear specified in the model input files. To exclude tower effects to the greatest extent possible and to ensure consistency with processing applied to experimental data, mean $\mathrm{C}_{\mathrm{n}}$ data were computed using only data from the upper half of the rotor disc.

Following YawDyn/AeroDyn model calibration for mean aerodynamic response, the same model was used to predict time varying aerodynamic response. Prediction of time varying aerodynamic response was accomplished by providing turbulent inflow input files to the calibrated YawDyn/AeroDyn model. These turbulent inflow files were generated using the NWTC TurbSim model, with inputs specified as follows.

The TurbSim grid was 13 points high by 13 points wide, corresponding to a height of $13.0 \mathrm{~m}$ and width of 13.0 $\mathrm{m}$. An IEC Kaimal model was chosen consistent with IEC Standard 61400-1, edition 3. Turbulence intensity was specified at 5.0, 10.0, and 15.0 percent, for each of five mean wind speeds $\left(U_{\infty}=5,10,15,20\right.$, and $\left.25 \mathrm{~m} / \mathrm{s}\right)$, yielding a total of 15 turbulent inflow input files. A power law wind profile with an exponent of zero was specified, to replicate the uniform mean inflow present during wind tunnel testing. To achieve stationary statistical characteristics for the turbulent inflow time series, an output time series of 600 seconds duration was specified.

\section{Results and Discussion}

\section{A. Reference Angle and Nondimensionalization}

Derivation of angle of attack and lift coefficient for rotating blades using measurements on or near the blade remains a challenging and essential area of inquiry [13,15,36-40]. However, in the current work, these dependencies were excluded to simplify physical relationships and focus on the blade flow field. This was done by analyzing local inflow angle (LFA) and normal force coefficient $\left(\mathrm{C}_{n}\right)$ instead of angle of attack and lift coefficient.

Normalization of aerodynamic forces also presents challenges. In the current work, normal force was nondimensionalized by local dynamic pressure. Local dynamic pressure was computed as the difference between test section static pressure $\left(\mathrm{p}_{\infty}\right)$ and local total pressure. Local total pressure was sensed at each full pressure tap distribution as the highest pressure in the tap distribution. 


\section{B. Identification of Separation and Reattachment}

Previous works have established the connection between airfoil boundary layer separation and reattachment, and surface pressure mean levels.[41] A surface pressure distribution exhibiting significant chordwise pressure gradient $(\mathrm{dp} / \mathrm{dx})$ signals attached or reattached flow, while an attenuated pressure gradient indicates separated flow. Other efforts established the correlation between lifting surface boundary layer separation and reattachment, and surface pressure temporal fluctuations for two-dimensional [42] and three-dimensional [43,44] flows. For both types of flows, boundary layer separation and reattachment elicit localized surface pressure fluctuations significantly greater than those observed at locations occupied by attached flow.

These generalized relationships for stationary geometries were successfully adapted to track boundary layer separation and shear layer impingement on the surface of the rotating UAE wind turbine blade during the NASA Ames wind tunnel experiment.[17,18] Later, these experimental surface characterizations were combined with validated computational results [19] to provide a cohesive portrayal of mean flow field behavior underlying rotational augmentation of aerodynamic loads on turbine blades.

To briefly summarize these previous works, for each radial location, the tap where maximum standard deviation in surface pressure occurred was identified as a location of either boundary layer separation or shear layer impingement. Boundary layer separation was distinguished from shear layer impingement by examining the change in pressure gradient. If the upstream gradient was appreciable and the downstream one essentially zero, then the feature was identified as boundary layer separation. Alternatively, if the upstream gradient was essentially zero and the downstream gradient was appreciable, then the feature was identified as shear layer impingement. Mean flow fields for boundary layer separation and shear layer impingement are schematically depicted in Figure 5.

In Figure 5, separation and impingement points are identified by the filled circular symbol on the blade upper (suction) surface. Chordwise distance between the separation point and trailing edge is defined as the separated length $\left(\mathrm{L}_{\mathrm{SEP}}\right)$. Similarly, the chordwise distance between the impingement point and leading edge is termed the impingement length $\left(\mathrm{L}_{\mathrm{IMP}}\right)$.
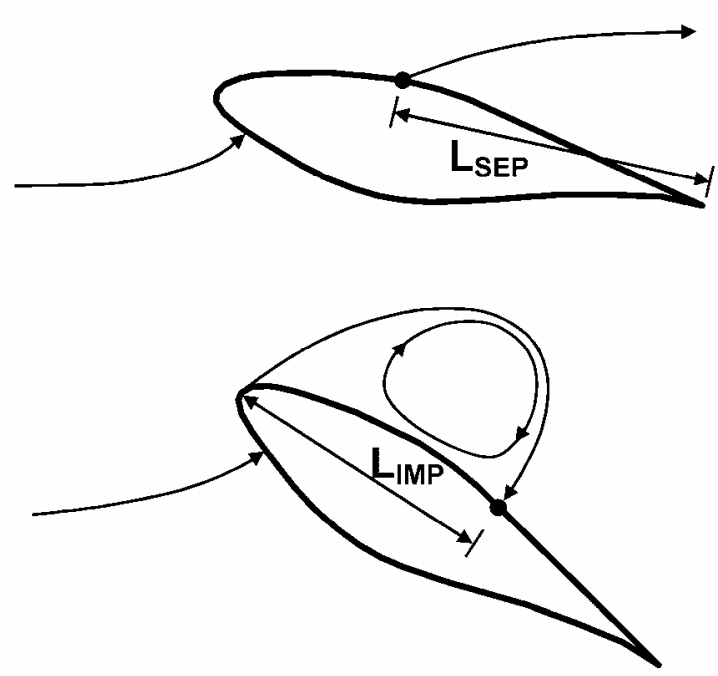

Figure 5. Definition of separated length $\left(\mathrm{L}_{\mathrm{SEP}}\right)$ and impingement length $\left(\mathrm{L}_{\mathrm{IMP}}\right)$.

\section{Separation/Impingement Location and $\mathbf{C}_{\mathbf{n}}$ Standard Deviation}

Using the criteria explained above, the mean chordwise locations of boundary layer separation or shear layer impingement were identified for test section speeds from $5 \mathrm{~m} / \mathrm{s}$ to $25 \mathrm{~m} / \mathrm{s}$, at $0.30 \mathrm{R}, 0.47 \mathrm{R}, 0.63 \mathrm{R}$, and $0.80 \mathrm{R}$. Data for $0.95 \mathrm{R}$ were available, but were not analyzed because of blade tip vortex proximity and associated confounding effects. Results are shown in Figures 6 through 9, along with $C_{n}$ standard deviation data. In each of these figures, the 21 values of LFA correspond to the 21 test section speeds from $5 \mathrm{~m} / \mathrm{s}$ to $25 \mathrm{~m} / \mathrm{s}$. In Figures 6 through 9 , separation is indicated by open circular symbols, and filled circular symbols denote impingement.

\section{1. $0.30 R$}

Figure 6 shows separation/impingement chordwise movement and $\mathrm{C}_{\mathrm{n}}$ standard deviation data for $\mathrm{r} / \mathrm{R}=0.30$. For $\mathrm{LFA}=4.7^{\circ}, 9.3^{\circ}$, and $13.9^{\circ}$, separation was detected at $0.56 \mathrm{c}$. This is consistent with visualization results obtained using a two-dimensional S809 airfoil.[45] At LFA $=18.5^{\circ}$, separation initially was detected at the trailing edge, at $\mathrm{LFA}=22.6^{\circ}$ progressed forward to $0.80 \mathrm{c}$. Shortly thereafter, separation arrived in the leading edge vicinity $(0.02 \mathrm{c})$ at $\mathrm{LFA}=26.4^{\circ}$ and remained there until LFA $=29.4^{\circ}$.

Impingement was first apparent at LFA $=32.5^{\circ}$ and $0.06 \mathrm{c}$, as the point of maximum $\mathrm{c}_{\mathrm{p}}$ standard deviation retreated from $0.02 \mathrm{c}$. Initial impingement movement was mildly responsive to LFA, with impingement moving aft to $0.10 \mathrm{c}$ as LFA increased to $35.2^{\circ}$. Further aft movement was more sensitive to LFA, with impingement advancing to the trailing edge as LFA increased to $42.3^{\circ}$. Thereafter, impingement remained at the trailing edge until LFA $=$ 
$48.5^{\circ}$. At this point, impingement began to advance forward again, halting at $\mathrm{x} / \mathrm{c}=0.56$ and remaining there until data acquisition ended.

$\mathrm{C}_{\mathrm{n}}$ standard deviation fluctuations generally were correlated with separation and impingement movement. Forward advance of the separation point from the trailing edge $(\mathrm{x} / \mathrm{c}=1.0)$ to the leading edge vicinity was accompanied by a significant and steady increase in $\mathrm{C}_{\mathrm{n}}$ standard deviation levels. As separation transitioned to impingement and moved aft from the leading edge, $C_{n}$ standard deviation initially increased to a local maximum of 0.178 , and then briefly decreased to 0.122 . Thereafter, $\mathrm{C}_{\mathrm{n}}$ standard deviation again began to rise with aft movement of impingement. This trend continued until maximum $\mathrm{C}_{\mathrm{n}}$ standard deviation was attained with impingement at the trailing edge. Finally, as impingement traveled forward toward midchord, $\mathrm{C}_{\mathrm{n}}$ standard deviation descended from 0.214 to 0.183 .
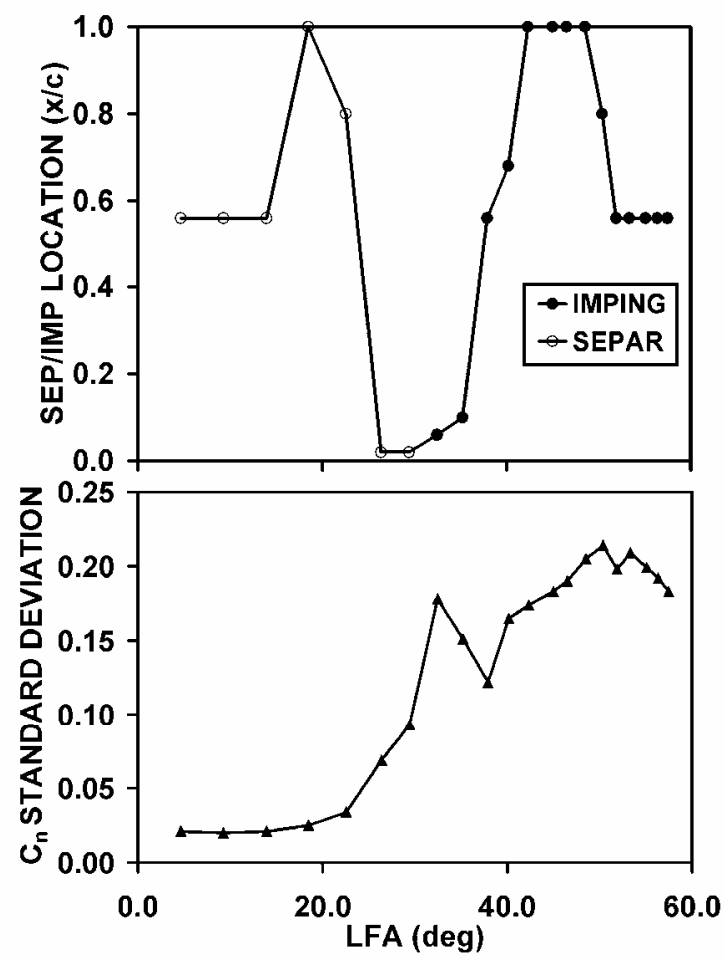

Figure 6. Separation/impingement chordwise movement (upper panel) and $C_{n}$ standard deviation (lower panel) at $0.30 \mathrm{R}$.

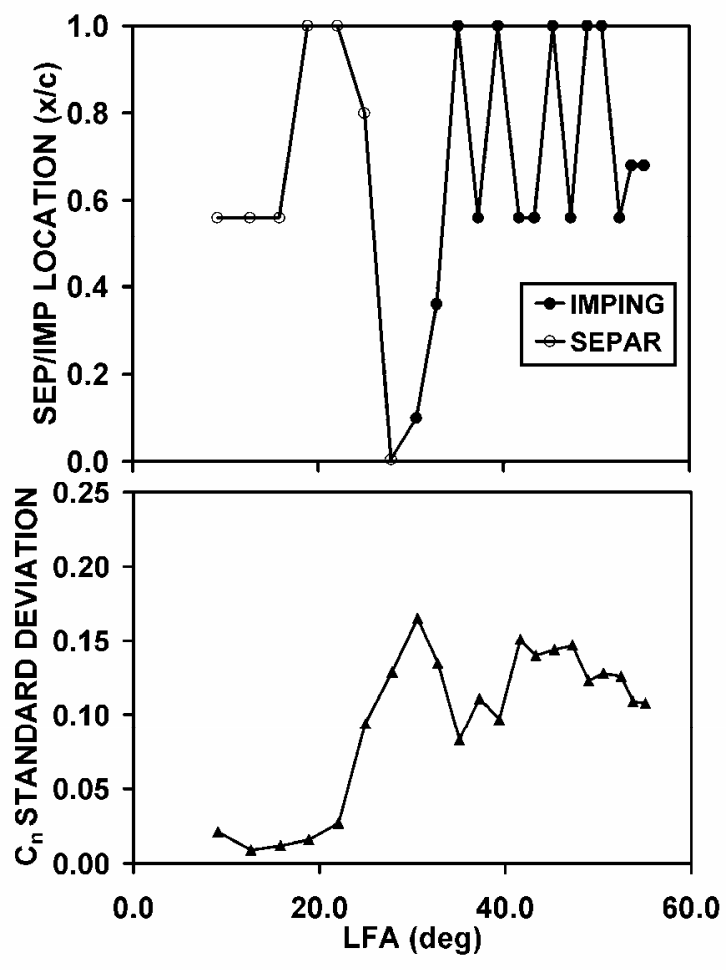

Figure 7. Separation/impingement chordwise movement (upper panel) and $C_{n}$ standard deviation (lower panel) at $0.47 R$.

\section{2. $0.47 R$}

Chordwise separation/impingement movement and $\mathrm{C}_{\mathrm{n}}$ standard deviation data for $\mathrm{r} / \mathrm{R}=0.47$ resembled those at $0.30 \mathrm{R}$, and are shown in Figure 7. For LFA $=9.1^{\circ}, 12.7^{\circ}$, and $15.8^{\circ}$, separation was detected at $0.56 \mathrm{c}$, again consistent with two-dimensional visualizations of the S809.[45] At LFA $=18.9^{\circ}$, separation initially appeared at the trailing edge, and remained there until LFA $=22.1^{\circ}$. Immediately thereafter, separation movement responded strongly to increasing LFA, reaching the leading edge vicinity at $0.005 \mathrm{c}$ at LFA $=27.8^{\circ}$.

Impingement was first observed immediately after separation arrived at the leading edge, at LFA $=30.6^{\circ}$. Subsequent impingement movement was responsive to LFA, with impingement progressing to the trailing edge as LFA increased to $35.1^{\circ}$. Thereafter, impingement remained on the aft portion of the blade, apparently oscillating between $1.0 \mathrm{c}$ and $0.56 \mathrm{c}$ while LFA increased to $55.1^{\circ}$. 
$\mathrm{C}_{\mathrm{n}}$ standard deviation fluctuations were again well correlated with separation and impingement movement. As the separation point moved from the trailing edge to the leading edge neighborhood, $\mathrm{C}_{\mathrm{n}}$ standard deviation levels increased monotonically and substantially to 0.129 . As separation transitioned to impingement and moved aft from the leading edge, $\mathrm{C}_{\mathrm{n}}$ standard deviation briefly increased to 0.165 , and then temporarily decreased to 0.083 . Thereafter, $\mathrm{C}_{\mathrm{n}}$ standard deviation increased and decreased in irregular fashion as impingement oscillated between $0.56 \mathrm{c}$ and $1.00 \mathrm{c}$.

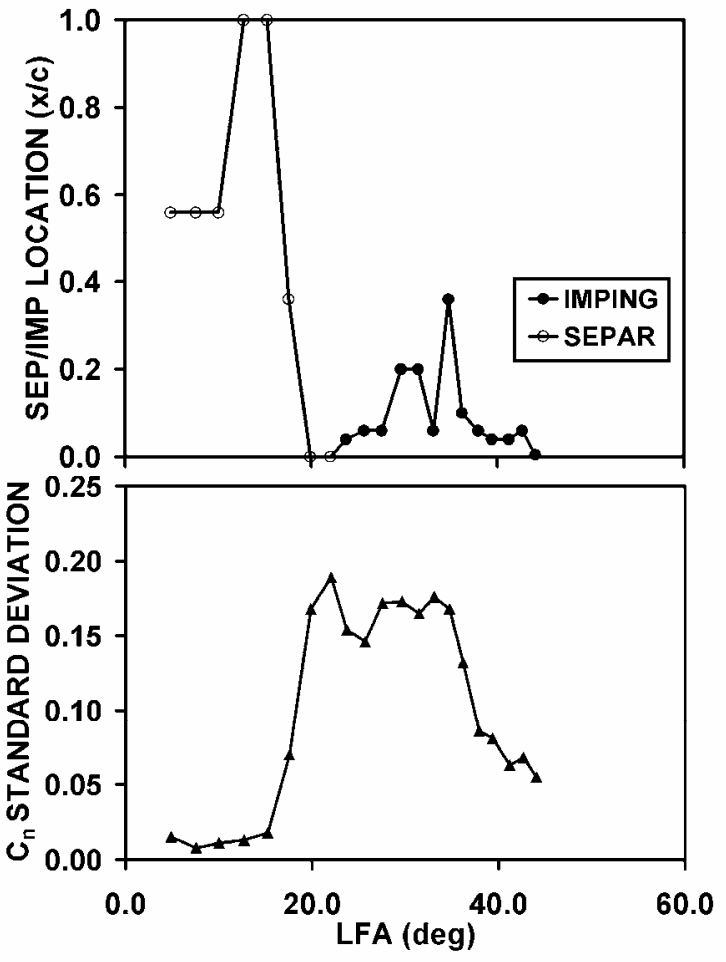

Figure 8. Separation/impingement chordwise movement (upper panel) and $C_{n}$ standard deviation (lower panel) at $0.63 R$.

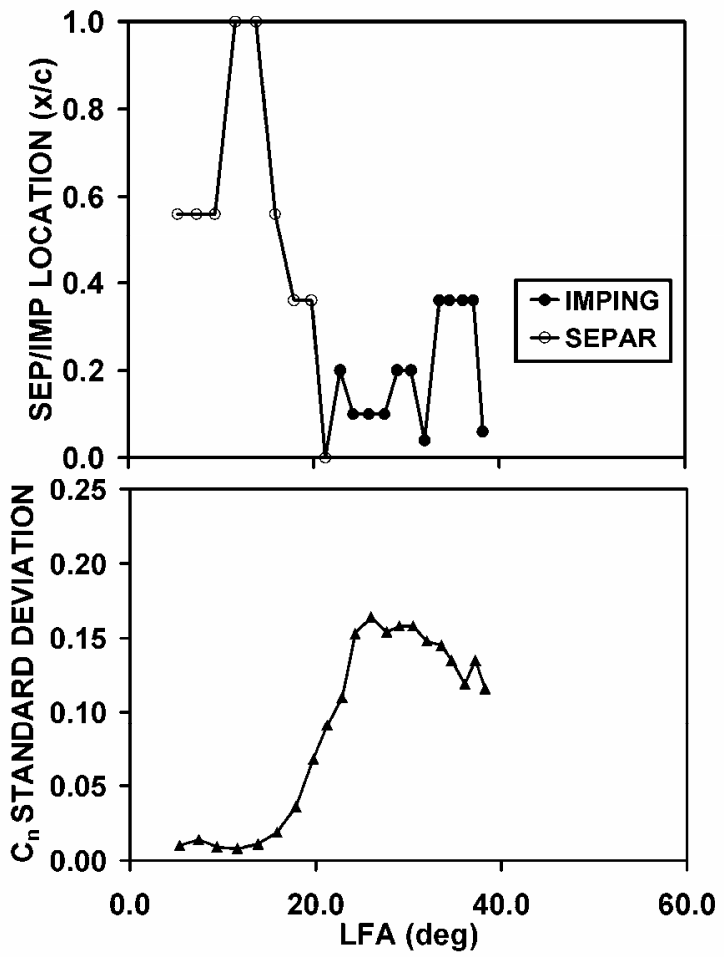

Figure 9. Separation/impingement chordwise movement (upper panel) and $C_{n}$ standard deviation (lower panel) at $0.80 \mathrm{R}$.

\section{3. $0.63 R$}

Separation movement at $\mathrm{r} / \mathrm{R}=0.63$, as shown in Figure 8, was similar to separation movement at $0.30 \mathrm{R}$ and $0.47 \mathrm{R}$. For $\mathrm{LFA}=4.9^{\circ}, 7.6^{\circ}$, and $10.0^{\circ}$, separation was observed at $0.56 \mathrm{c}$. As before, this early midchord detection of separation agreed with two-dimensional visualizations of the S809.[45] At LFA $=12.7^{\circ}$, separation was first detected at the trailing edge, and then moved responsively forward with increasing LFA. At LFA $=19.9^{\circ}$, separation had reached the leading edge, and remained there until LFA $=22.0^{\circ}$.

Impingement was first observed at $0.04 \mathrm{c}$, at $\mathrm{LFA}=23.7^{\circ}$. Subsequently, impingement movement was somewhat erratic and only moderately responsive to LFA. In contrast to the $0.30 \mathrm{R}$ and $0.47 \mathrm{R}$ locations, impingement did not reach the blade trailing edge region. Instead, impingement retreated in irregular fashion aft to $0.36 \mathrm{c}$ as LFA increased to $34.7^{\circ}$. Subsequently, impingement advanced steadily forward with further increases in LFA, reaching $0.005 \mathrm{c}$ at $\mathrm{LFA}=44.1^{\circ}$.

At $0.63 \mathrm{R}, \mathrm{C}_{\mathrm{n}}$ standard deviation fluctuations again correlated well with separation and impingement movement. Forward travel of the separation point from the trailing edge to the leading edge occurred concurrently with a substantial and monotonic rise in $\mathrm{C}_{\mathrm{n}}$ standard deviation to a maximum of 0.189 . Immediately after impingement supplanted separation, the impingement point moved aft in erratic fashion to its $0.36 \mathrm{c}$, at the same time that $\mathrm{C}_{\mathrm{n}}$ standard deviation varied in an irregular manner. Local maxima in aft impingement point travel at LFA $=29.6^{\circ}$ and $34.7^{\circ}$ were closely correlated to local maxima in $C_{n}$ standard deviation that occurred at LFA $=29.6^{\circ}$ and $33.1^{\circ}$. 


\section{4. $0.80 R$}

Figure 9 shows separation/impingement and $\mathrm{C}_{\mathrm{n}}$ standard deviation data for $\mathrm{r} / \mathrm{R}=0.80$. For $\mathrm{LFA}=5.3^{\circ}, 7.4^{\circ}$, and $9.4^{\circ}$, separation was detected at $0.56 \mathrm{c}$. As at the other three radial locations, this observation was consistent with surface flow visualizations performed on a two-dimensional S809.[45] At LFA $=11.6^{\circ}$, separation initially was observed at the trailing edge, progressed rapidly forward in response to rising LFA, and at LFA $=21.3^{\circ}$ reached the leading edge.

Impingement was first observed at $0.20 \mathrm{c}$, at LFA $=22.9^{\circ}$. Subsequently, impingement generally moved in an aft direction, but did so in sporadic fashion, stabilizing temporarily at $0.10 \mathrm{c}, 0.20 \mathrm{c}$, and $0.36 \mathrm{c}$ before ending at $0.10 \mathrm{c}$ at $\mathrm{LFA}=38.2^{\circ}$. As at $0.63 \mathrm{R}$, impingement moved aft no farther than $0.36 \mathrm{c}$.

$\mathrm{C}_{\mathrm{n}}$ standard deviation levels again were linked closely to mean separation and impingement movement. At 0.80R, separation moved steadily forward from the trailing edge to the leading edge. At the same time, $C_{n}$ standard deviation increased substantially and uniformly from 0.015 to 0.091 . Thereafter, the impingement point traveled generally aft with infrequent disruptions, at the same time that $C_{n}$ standard deviation decreased from 0.164 to 0.116 , also exhibiting sporadic interruptions.

\section{D. $C_{n}$ Standard Deviation Correlation with Separation/Impingement Length}

Figures 6 through 9 imply that a consistent relationship exists between $C_{n}$ standard deviation levels and mean separation/impingement length. To more clearly distinguish this relationship, $\mathrm{C}_{\mathrm{n}}$ standard deviation was correlated with separation length in Figure 10, and with impingement length in Figure 11. As before, separation length and impingement length are defined as shown in Figure 5.

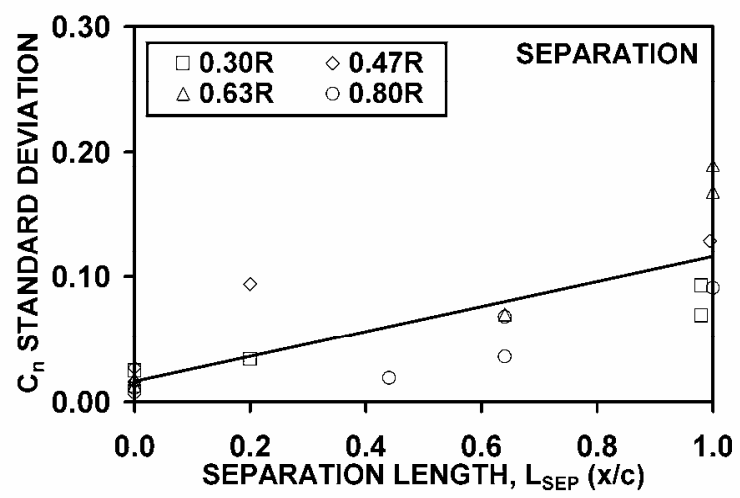

Figure 10. Correlation between $C_{n}$ standard deviation and separation length $\left(\mathrm{L}_{\mathrm{SEP}}\right)$, for all four radial locations.
In Figure 10, for a separation length of $0.0 \mathrm{c}$ (separation at trailing edge), $\mathrm{C}_{\mathrm{n}}$ standard deviations for all four radial locations were grouped tightly around a value of approximately 0.02. As separation moved toward the leading edge and separation length increased, $\mathrm{C}_{\mathrm{n}}$ standard deviation increased in steady, monotonic fashion for all four radial stations. The solid line extending diagonally across the lower part of the plot is an aggregate linear least squares fit to all plotted data points, and thus represents an average correlation across all four radial locations. Slope of this linear fit is 0.100 .

Clearly, data points corresponding to the four radial locations deviate from the linear fit. Irregular deviation from the linear fit can be partially attributed to comparatively coarse chordwise pressure tap resolution over the aft portion of the blade surface. However, careful examination of Figure 10 reveals that the points for the $0.47 \mathrm{R}$ and $0.63 \mathrm{R}$ locations assume a consistently steeper slope than those for $0.30 \mathrm{R}$ and $0.80 \mathrm{R}$. Thus, three dimensional aerodynamic interactions can be identified as a source for systematic deviations from the aggregate linear fit.

In Figure 11, for impingement lengths of $0.0 \mathrm{c}$ (impingement at leading edge) to 1.0c (impingement at trailing edge), $C_{n}$ standard deviation for all four radial locations was confined to a range of approximately 0.1 to 0.2 . As before, a linear least squares fit was applied to all data points in the Figure 11 plot, and is shown by the solid line extending across the center of the plot. The slope of this aggregate linear fit is 0.023 , which is significantly shallower than the slope of 0.100 for the line fit to the separation length data in Figure 10.

As in Figure 10, data points in Figure 11 deviate visibly from the linear fit. Sporadic deviation from the linear fit is partially attributable to sparse chordwise pressure tap spacing over the aft blade chord. However, strong aerodynamic three-dimensionality previously has

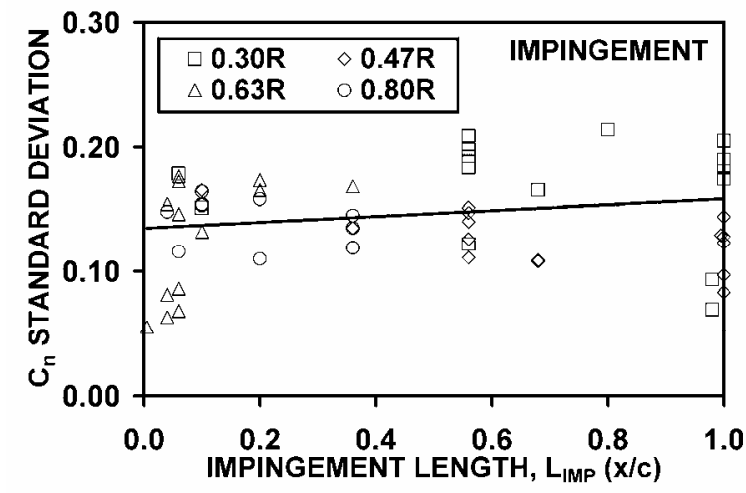

Figure 11. Correlation between $C_{n}$ standard deviation and impingement length $\left(\mathrm{L}_{\mathrm{IMP}}\right)$, for all four radial locations. 
been identified in the UAE operating range corresponding to the Figure 11 data.[19] This blade flow field change introduces spanwise flow components that alter impingement length, and modifies the mechanisms for time varying aerodynamic force generation.

Comparing the aggregate linear least squares fit for separation (Figure 10) with that for impingement (Figure 11) leads to two clear observations. First, time varying aerodynamic force levels are, with only isolated exceptions, significantly higher for an impinging flow field than for a separated flow field. Second, the slope of the linear fit for separation (0.100) is four times steeper than that for impingement $(0.023)$. This indicates that above-surface fluid dynamics responsible for time varying aerodynamic force production respond more sensitively to aerodynamic surface state during separation than during impingement.

\section{E. $\mathbf{C}_{\mathbf{n}}$ Standard Deviation from Turbulent Atmospheric Inflow}

Thus far in the current work, the only $\mathrm{C}_{\mathrm{n}}$ standard deviations considered have been those produced by interactions occurring spontaneously in separated and impinging blade flow fields. This exclusion was enabled by the NASA Ames $80 \mathrm{ft} \times 120 \mathrm{ft}$ wind tunnel, which provided an inflow environment free of significant inflow turbulence or velocity gradients.[32] To quantify $\mathrm{C}_{\mathrm{n}}$ standard deviations that would occur in response to turbulent atmospheric inflow, the UAE was modeled using the YawDyn[33] and AeroDyn[34] models, in conjunction with turbulent inflow files from TurbSim[35].

Figures 12 and 13 show $C_{n}$ standard deviation data from the UAE wind tunnel test along with $C_{n}$ standard deviation data extracted from YawDyn/TurbSim model output files. For each radial location, $C_{n}$ standard deviation data were extracted from model output files for three turbulence intensities $(5,10$, and 15 percent), for each of five mean wind speeds $\left(\mathrm{U}_{\infty}=5,10,15,20\right.$, and $\left.25 \mathrm{~m} / \mathrm{s}\right)$.

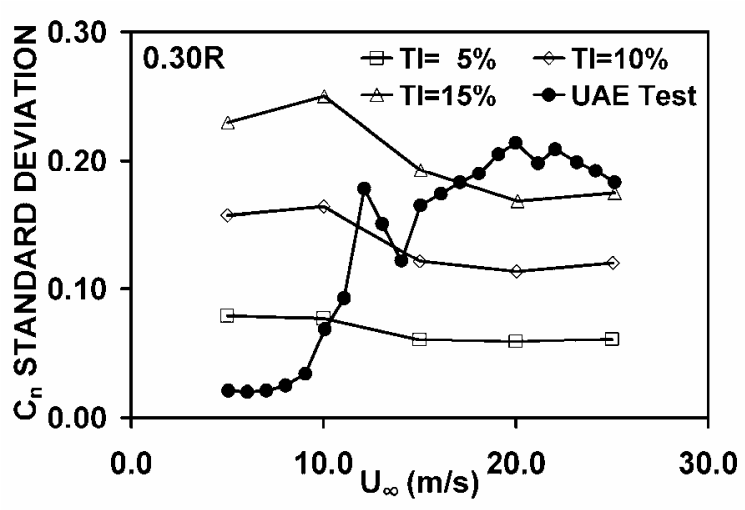

Figure 12. $C_{n}$ standard deviations measured by UAE and predicted by YawDyn/TurbSim at 0.30R.

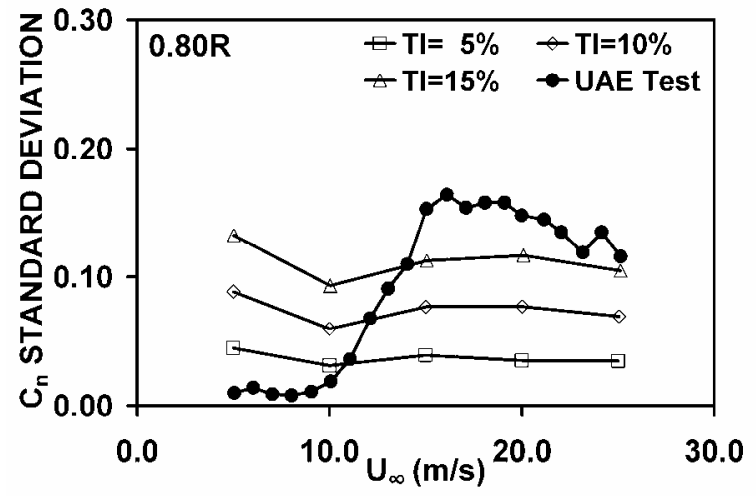

Figure 13. $C_{n}$ standard deviations measured by UAE and predicted by YawDyn/TurbSim at 0.80R.

Figure 12 shows $\mathrm{C}_{\mathrm{n}}$ standard deviation test measurements and model predictions for the $0.30 \mathrm{R}$ radial location. UAE test data in this figure are the same as those in the lower panel of Figure 6, except that the test data in Figure 12 are plotted as a function of $U_{\infty}$ to maintain consistency with the model data. Similar to Figure $6, C_{n}$ standard deviation levels for the test data exhibit subdued levels for low $U_{\infty}$, and increase steadily with $U_{\infty}$. The three modeled turbulence intensity levels produce three widely separated $C_{n}$ standard deviation levels, all of which are significant in magnitude. UAE test data points representing a separated flow field reach $\mathrm{C}_{\mathrm{n}}$ standard deviation levels corresponding to turbulence intensities of 5 to 10 percent. Some UAE test data points for an impinging flow field lie between the 10 and 15 percent turbulence intensity curves, and several more reach $C_{n}$ standard deviation levels exceeding those elicited by turbulence intensities of 15 percent.

Figure 13 shows $\mathrm{C}_{\mathrm{n}}$ standard deviation test measurements and model predictions for the $0.80 \mathrm{R}$ radial location. UAE test data in Figure 13 are the same as those shown in the lower panel of Figure 9, though the test data in Figure 13 have been plotted against $U_{\infty}$ for consistency with model data. As in Figure 9, test data $C_{n}$ standard deviation levels assume attenuated levels for low $\mathrm{U}_{\infty}$, and increase substantially with $\mathrm{U}_{\infty}$. The three modeled turbulence intensities of 5,10, and 15 percent yield three clearly delineated $\mathrm{C}_{\mathrm{n}}$ standard deviation levels. While magnitudes of these curves are lower than those at $0.30 \mathrm{R}$, all three nonetheless remain significant in magnitude. UAE test data points for separated flow fields reach $\mathrm{C}_{\mathrm{n}}$ standard deviation levels represented by turbulence intensities of 10 to 15 
percent. All of the UAE test data points representing impinging flow fields lie above the 15 percent turbulence intensity curve, with many of these points lying significantly above this curve.

Figures 12 and 13 clearly show that blade operation in either the stalled regime in quiescent inflow, or in the unstalled regime in turbulent inflow, produces $\mathrm{C}_{\mathrm{n}}$ standard deviations of comparable and substantial magnitude. The turbulence intensity range of 5 to 15 percent in Figures 12 and 13 approximates the turbulence intensity range of 13 to 20 percent encompassed by various design standards.[46] Similar data were analyzed for $0.47 \mathrm{R}$ and $0.63 \mathrm{R}$, revealing trends consistent with those shown by Figures 12 and 13. It is important to note that these data and analyses are not intended to predict $\mathrm{C}_{\mathrm{n}}$ standard deviation levels that could be expected for a blade operating in the stalled regime in a turbulent inflow.

\section{Conclusions}

Blade surface pressure data were acquired from a full-scale horizontal axis wind turbine tested under axisymmetric conditions in the NASA Ames $80 \mathrm{ft}$ x $120 \mathrm{ft}$ wind tunnel. Records of time varying surface pressure and normal force were analyzed to extract mean separation and impingement location and normal force coefficient standard deviation during operating conditions that included rotational augmentation. Complementary model predictions of time varying normal force coefficient standard deviation also were provided for turbulent inflow conditions. These data and analyses support the following conclusions.

Normal force coefficient standard deviation varies considerably with local inflow conditions, which in turn determine blade flow field structure.

Normal force coefficient standard deviation correlates well with mean flow field spatial scales at the blade surface, specifically mean separated length and mean impingement length.

Normal force coefficient standard deviation is substantially higher for impinging blade flow fields than for separating blade flow fields.

Normal force coefficient standard deviation responds more sensitively to blade surface mean flow field state for separating flow fields than for impinging flow fields.

Normal force coefficient standard deviations observed for quiescent inflow are of the same magnitude as normal force coefficient standard deviations produced by routine turbulent inflows.

This work characterizes previously undocumented physical relationships that govern aerodynamic force time variations that take place in connection with rotational augmentation on rotating wind turbine blades. This and other research will help improve the accuracy and reliability of aerodynamic predictions for wind energy machine design and analysis.

\section{Acknowledgment}

The wind turbine data used in this investigation were acquired from the National Wind Technology Center (NWTC) Unsteady Aerodynamics Experiment (UAE). The wind turbine and instrumentation were designed, fabricated, installed, and maintained by Mr. Jason Cotrell, Mr. Lee Jay Fingersh, and Mr. David Jager. The UAE was installed and tested in the NASA Ames $80 \mathrm{ft}$ x $120 \mathrm{ft}$ National Full-Scale Aerodynamics Complex by these NWTC personnel, with the assistance, advice, and encouragement of numerous NASA Ames engineers, scientists, and technicians.

\section{References}

[1] Butterfield, C., A. Hansen, D. Simms, and G. Scott, "Dynamic Stall on Wind Turbine Blades," NREL/TP-2574510, Dec. 1991. Golden, CO: National Renewable Energy Laboratory.

[2] Shipley, D., M. Miller, M. Robinson, M. Luttges, and D. Simms, "Evidence that Aerodynamic Effects, Including Dynamic Stall, Dictate HAWT Structure Loads and Power Generation in Highly Transient Time Frames," NREL/TP-441-7080, Aug. 1994. Golden, CO: National Renewable Energy Laboratory.

[3] Shipley, D., M. Miller, and M. Robinson, "Dynamic Stall Occurrence on a Horizontal Axis Wind Turbine Blade," NREL/TP-442-6912, Jul. 1995. Golden, CO: National Renewable Energy Laboratory.

[4] Robinson, M., R. Galbraith, D. Shipley, and M. Miller, "Unsteady Aerodynamics of Wind Turbines," AIAA 950526, Jan 1995.

[5] Huyer, S., D. Simms, and M. Robinson, "Unsteady Aerodynamics Associated with a Horizontal Axis Wind Turbine," AIAA J., v. 34, n. 7, Jul. 96, pp. 1410-1419.

[6] Robinson, M., D. Simms, M. Hand, and S. Schreck, "Horizontal Axis Wind Turbine Aerodynamics: ThreeDimensional, Unsteady, and Separated Flow Influences," FEDSM99-S295-01, $3^{\text {rd }}$ ASME/JSME Joint Fluids Engineering Conference, July, 1999. 
[7] Schreck, S., M. Robinson, M. Hand, and D. Simms, "HAWT Dynamic Stall Response Asymmetries Under Yawed Flow Conditions," AIAA 2000-0040, Jan. 2000.

[8] Schreck, S., M. Robinson, M. Hand, and D. Simms, "Contrasting Blade Flow Field Archetypes in the HAWT Operating Regime,"AIAA 2000-0036,Jan 2001.

[9] Himmelskamp, H., "Profiluntersuchungen an einem umlaufenden Propeller", Dissertation, Gottingen 1945; Mitt. Max-Planck-Institut fur Stromungsforschung Gottingen Nr. 2, 1950.

[10] Banks, W., and G. Gadd, "Delaying Effect of Rotation on Laminar Separation," AIAA J., v. 1, n. 4, Apr. 1963, pp. 941-942.

[11] McCroskey, W., and P. Yaggy, "Laminar Boundary Layers on Helicopter Rotors in Forward Flight," AIAA J., v. 6, n. 10, Oct. 1968, pp. 1919-1926.

[12] McCroskey, W. J., "Measurements of Boundary Layer Transition, Separation and Streamline Direction on Rotating Blades," NASA TN D-6321, Apr. 1971.

[13] Madsen, H., and H. Christensen, "On the Relative Importance of Rotational, Unsteady and Three-Dimensional Effects on the HAWT Rotor Aerodynamics," Wind Engineering, v. 14, n. 6, 1990, pp. 405-415.

[14] Barnsley, M., and Wellicome, J., "Wind Tunnel Investigation of Stall Aerodynamics for a $1.0 \mathrm{~m}$ Horizontal Axis Rotor," J. of Wind Engineering and Industrial Aerodynamics, v. 39, 1992, pp. 11-21.

[15] Ronsten, G., "Static Pressure Measurements on a Rotating and a Non-Rotating $2.375 \mathrm{~m}$ Wind Turbine Blade. Comparison with 2D Calculations," J. of Wind Engineering and Industrial Aerodynamics, v. 39, 1992, pp. 105-118.

[16] Schreck, S., and Robinson, M., "Rotational Augmentation of Horizontal Axis Wind Turbine Blade Aerodynamic Response," Wind Energy, v. 5, n. 2/3, pp. 133-150, Apr.-Sep. 2002.

[17] Schreck, S., and Robinson, M., "Boundary Layer State and Flow Field Structure Underlying Rotational Augmentation of Blade Aerodynamic Response," J. of Solar Energy Eng., v. 125, pp. 448-456, November 2003.

[18] Schreck, S., and Robinson, M., "Structures and Interactions Underlying Rotational Augmentation of Blade Aerodynamic Response," AIAA-2003-0520, January 2003.

[19] Schreck, S., Sørensen, N., and Robinson, M., "Aerodynamic Structures and Processes in Rotationally Augmented Flow Fields," to appear, Wind Energy.

[20] Schreck, S., and Robinson, M., "Tip Speed Ratio Influences on Rotationally Augmented Boundary Layer Topology and Aerodynamic Force Generation," AIAA-2004-0663, January 2004.

[21] Schreck, S., and Robinson, M., "Unsteadiness in HAWT Blade Aerodynamic Forces and Flow Field Structures During Rotational Augmentation," AIAA-2005-0776, January 2005.

[22] Eggers, A., and R. Digumarthi, "Approximate Scaling of Rotational Effects on Mean Aerodynamic Moments and Power Generated by CER Blades Operating in Deep-Stalled Flow," $11^{\text {th }}$ ASME Wind Energy Symposium, Jan. 1992.

[23] Snel, H., R. Houwink, and W. Piers, "Sectional Prediction of 3D Effects for Separated Flow on Rotating Blades," $18^{\text {th }}$ European Rotorcraft Forum, Sept. 1992.

[24] Tangler, J., and M. Selig, "An Evaluation of an Empirical Model for Stall Delay due to Rotation for HAWTS," NREL/CP 440-23258, Golden, CO: National Renewable Energy Laboratory.

[25] Corrigan, J., and J. Schillings, "Empirical Model for Stall Delay Due to Rotation," American Helicopter Society Aeromechanics Specialist Conf., Jan. 1994.

[26] Butterfield, C., W. Musial, and D. Simms, (1992). “Combined Experiment Phase I Final Report" NREL/TP257-4655. Golden, CO: National Renewable Energy Laboratory.

[27] Miller, M., D. Shipley, T. Young, M. Robinson, M. Luttges, and D. Simms (1995), "Combined Experiment Phase II Data Characterization.” NREL/TP 442-6916, Golden, CO: National Renewable Energy Laboratory.

[28] Fingersh, L., D. Simms, C. Butterfield, and M. Jenks, "An Overview of the Unsteady Aerodynamics Experiment Phase III Data Acquisition System and Instrumentation," ASME Energy and Environment Expo '95, Houston, TX, Jan.-Feb. 1995.

[29] Acker, T., "Further Analysis of Data from the Unsteady Aerodynamics Experiment, Phase III and Phase IV," Task 2 Report, Subcontr. XAT-8-18211-01, Golden, CO: National Renewable Energy Laboratory.

[30] Hand, M., Simms, D., Fingersh, L., Jager, D., Cotrell, J., Schreck, S., and Larwood, S., "Unsteady Aerodynamics Experiment Phase VI: Wind Tunnel Test Configurations and Available Data Campaigns," NREL/TP-500-29955, December 2001, Golden, CO: National Renewable Energy Laboratory.

[31] Giguere, P., and M. Selig, "Design of a Tapered and Twisted Blade for the NREL Combined Experiment Rotor," NREL/SR 500-26173, Apr. 1999, Golden, CO: National Renewable Energy Laboratory.

[32] Zell, P., "Performance and Test Section Flow Characteristics of the National Full-Scale Aerodynamics Complex 80- by 120-Foot Wind Tunnel," NASA TM 103920, January 1993. 
[33] Laino, D., and Hansen, A. C., "YawDyn User's Guide," available electronically at http://wind/designcodes/simulators/yawdyn/YawDyn.pdf, April 2003.

[34] Laino, D., and Hansen, A. C., "AeroDyn User's Guide," available electronically at http://wind/designcodes/simulators/aerodyn/AeroDyn.pdf, December 2002.

[35] Jonkman, B., and Buhl, M., "TurbSim User's Guide," NREL/TP-500-39797, September 2006, Golden, CO: National Renewable Energy Laboratory.

[36] Brand, A., "To Estimate the Angle of Attack of an Airfoil from the Pressure Distribution," ECN Technical Report, ECN-R-94-002, January 1994.

[37] Schepers, J. G., Brand, A., Bruining, A, Hand, M., Infield, D., Madsen, H., Maeda, T., Paynter, J., van

Rooij, R., Shimizu, Y., Simms, D., and Stefanatos, N., "Final Report of IEA Annex XVIII: Enhanced Field

Rotor Aerodynamics Database", ECN-C--02-016, Energy Research Centre of The Netherlands, Petten, The

Netherlands, February 2002.

[38] Shipley, D., Miller, M., Robinson, M., and Luttges, M., "Techniques for the Determination of Local Dynamic Pressure and Angle of Attack on a Horizontal Axis Wind Turbine," NREL Technical Report TP-442-7393, May 1995.

[39] Whale, J., Fisichella, C., and Selig, M., "Correcting Inflow Measurements from HAWTs Using a LiftingSurface Code," AIAA 99-0040, 1999 ASME Wind Energy Symposium, January 1999.

[40] van Bussel, G., "The Aerodynamics of Horizontal Axis Wind Turbine Rotors Explored with Asymptotic Expansion Methods," Thesis Technische Universiteit Delft, The Netherlands, 1995.

[41] McCullough, G., and Gault, D., "Examples of Three Representative Types of Airfoil-Section Stall at Low Speed," NACA TN-2502, Sept. 1952.

[42] Mabey, D., "Analysis and Correlation of Data on Pressure Fluctuations in Separated Flow," J. of Aircraft, v. 9, n. 9, pp. 642-645, Sept. 1972.

[43] Forsching, H., and Zingel, H., "Motion-Induced Unsteady Airloads on an Oscillating Low-Aspect-Ratio Trapezoidal Half-Wing in Separated Flow," J. of Fluids and Structures, v. 2, pp. 515-539, 1988.

[44] Jupp, M., Coton, F., Green, R., and Galbraith, R., "An Analysis of a Pitching Delta Wing Using High Resolution Pressure Measurements," AIAA-98-2743, Jun. 1998.

[45] Somers, D., "Design and Experimental Results for the S809 Airfoil," NREL/SR-440-6918, Jan. 1997, Golden, CO: National Renewable Energy Laboratory.

[46] Burton, T., Sharpe, D., Jenkins, N., and Bossanyi, E., Wind Energy Handbook, John Wiley and Sons Ltd., Chichester, 2001, p. 22. 


\section{REPORT DOCUMENTATION PAGE}

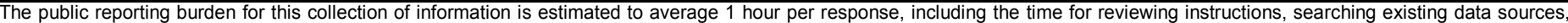

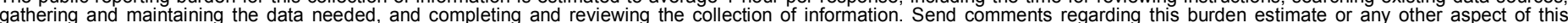

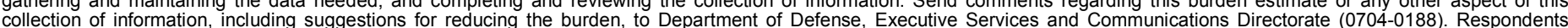

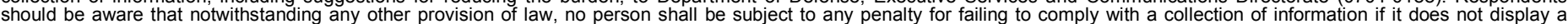

should be aware that notwithstandin

PLEASE DO NOT RETURN YOUR FORM TO THE ABOVE ORGANIZATION.

\begin{tabular}{l|l|l|l} 
1. REPORT DATE $(D D-M M-Y Y Y Y)$ & 2. & REPORT TYPE & 3. DATES COVERED (FrOm - TO)
\end{tabular}

January 2007

Conference paper

4. TITLE AND SUBTITLE

Rotationally Augmented Flow Sturctures and Time Varying Loads

on Turbine Blades: Preprint 5a. CONTRACT NUMBER

DE-AC36-99-G010337

5b. GRANT NUMBER

5c. PROGRAM ELEMENT NUMBER

5d. PROJECT NUMBER

NREL/CP-500-40982

5e. TASK NUMBER

WER7.2701

5f. WORK UNIT NUMBER
7. PERFORMING ORGANIZATION NAME(S) AND ADDRESS(ES)

National Renewable Energy Laboratory

1617 Cole Blvd.

Golden, CO 80401-3393
8. PERFORMING ORGANIZATION REPORT NUMBER

NREL/CP-500-40982

9. SPONSORING/MONITORING AGENCY NAME(S) AND ADDRESS(ES)

10. SPONSOR/MONITOR'S ACRONYM(S) NREL

11. SPONSORING/MONITORING AGENCY REPORT NUMBER

12. DISTRIBUTION AVAILABILITY STATEMENT

National Technical Information Service

U.S. Department of Commerce

5285 Port Royal Road

Springfield, VA 22161

13. SUPPLEMENTARY NOTES

14. ABSTRACT (Maximum 200 Words)

Blade rotation routinely and significantly augments aerodynamic loads during zero yaw operation of horizontal axis wind turbines. To better understand the flow physics underlying this phenomenon, time dependent blade surface pressure data were acquired from the NREL Unsteady Aerodynamics Experiment.

15. SUBJECT TERMS

wind energy; wind turbines; wind turbine blades; Unsteady Aerodynamics Experiment; NASA Ames;

\begin{tabular}{l}
\hline \multicolumn{3}{|l|}{ 16. SECURITY CLASSIFICATION OF: } \\
\hline \begin{tabular}{l|l|l|} 
a. REPORT & b. ABSTRACT & c. THIS PAGE \\
Unclassified & Unclassified & Unclassified \\
& & \\
\hline
\end{tabular} \\
\hline
\end{tabular}

\begin{tabular}{|c|c|}
\hline $\begin{array}{l}\text { 17. LIMITATION } \\
\text { OF ABSTRACT }\end{array}$ & $\begin{array}{l}\text { 18. NUMBER } \\
\text { OF PAGES }\end{array}$ \\
\hline UL & \\
\hline
\end{tabular}

19a. NAME OF RESPONSIBLE PERSON

19b. TELEPHONE NUMBER (Include area code) 